\title{
Mekanik Ventilasyon Ayırma Yöntemleri ve Hemşirenin Rolü
}

\author{
Canan Kaş Güner ${ }^{1} \oplus$, Sevinç Kutlutürkan²®
}

'Kastamonu Üniversitesi, Tıbbi Hizmetler ve Teknikler, Kastamonu, Türkiye

${ }^{2}$ Gazi Üniversitesi, Hemşirelik Fakültesi, Ankara, Türkiye

Canan Kaş Güner, Öğr. Gör. Sevinç Kutlutürkan, Doç. Dr.
Illetişim:

Öğr. Gör. Canan Kaş Güner

Sümer Mah. Şehit Mehmet Sözen Cad. No: 20, Taşköprü/ Kastamonu, Türkiye Tel: +905385830095

E-Posta: canankas@gmail.com
Gönderilme Tarihi : 280 cak 2019

Revizyon Tarihi : 27 Mart 2019

Kabul Tarihi : : 07 Nisan 2019

\section{ÖZET}

Mekanik ventilatörden ayırma, solunum desteğiyle mekanik ventilatöre bağlanan hastanın destekten ve entübasyon tüpünden ayrılmasını içeren süreçtir. Bu süreçte, solunum yükü ventilatörden hastaya geçer. Mekanik ventilatörden ayırma işlemi aşamalarında ileri hemşirelik bilgisi ve uygulaması gereklidir. Hemşirenin solunum fonksiyonlarındaki değişimleri izlemesi ve doğru yönlendirmesi mekanik ventilatörden ayırmanın gecikmesini engelleyerek sorunların erken dönemde saptanmasını sağlar. Bu derlemede, solunum işinin ventilatörden bireyin kontrolüne geçişinin sağlanması sürecinde kullanılan yöntemler ve uygulanan farklı yöntemlerdeki ortak hemşirelik uygulamaları ele alınmıştır.

Anahtar sözcükler: Mekanik ventilatör, ayırma yöntemleri, hemşire

\section{NURSE'S ROLE AND RESPONSIBILITY IN MECHANICAL VENTILATION AND WEANING AND ITS METHODS}

\section{ABSTRACT}

Weaning from mechanical ventilation can be defined as the process of abruptly or gradually withdrawing ventilatory support and removing the intubation tube (extubation). In this process, the respiratory load is shifted from the ventilator to the patient's respiratory system. Practical knowledge of experienced nurses in mechanical ventilation and skills in the weaning process steps are required. Monitoring the nurses (Or A close monitoring from the nurses!?) and a correct orientation about the changes allow early detection of any problems by preventing delayed weaning. In this study, the methods used in the transition of the ventilatation from the mechanical ventilator to the control of the patient in addition to common nursing practices in different methods of mechanical ventilation are discussed.

Keywords: Mechanical ventilator, weaning methods, nurse

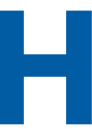

astanın kendi solunumunu yapabileceği zamana kadar yapay bir cihaz yardımıyla solunumunu sürdürmesi mekanik ventilasyon (MV) olarak adlandırılır (1). Mekanik ventilatörden ayırma; solunum desteğine ihtiyacın ortadan kalkması ile aşamalı olarak mekanik ventilatör desteğinin sonlandırımasıdır (2). Mekanik ventilatörden ayırma sürecinin başarısı 24-48 saat süreyle hastanın ventilatör desteğine gereksinim duymaksızın spontan solunumunu sürdürebilmesidir (3).

Ventilatörden ayırma işlemini Crocker (2009) (4) bakımın sürekliliği, hastanın tanınması ve hasta merkezli, bireyselleştirilmiş ayırma planlarının geliştirilmesi olarak tanımlar. Ayırma sürecinde hemşire, hastanın bireysel ihtiyaçlarını belirleyip bakım 
gereksinimlerini karşıladığında ventilatörden ayrılma süresinin kısalmasını sağlar (5). Ventilatörden ayırma işlemi, standart bir protokolün tüm hastalarda uygulanmasının zor olması nedeniyle ayırma işleminin belirli algoritmalar doğrultusunda yapılıp yapılmaması tartışmalı bir konu$\operatorname{dur}(2,3,6,7)$.

$\mathrm{Bu}$ derlemede, solunum işinin ventilatörden bireye kaydırılması sırasında kullanılan yöntemler ve uygulanan farklı yöntemlerdeki ortak hemşirelik uygulamaları ele alınmıştır.

\section{Mekanik ventilatörden ayırma yöntemleri}

\section{T-tüp yöntemi}

T-tüp yöntemi, bireyin ventilatör desteği olmadan solumasıdır (2). Bu yöntemde, endotrakeal tüpe bir T-parçası takılır, T-parçasının bir tarafından nemlendirilmiş oksijen verilir, diğer tarafından nefes verme süreci gerçekleşir. Bireyin t-parçasında kalma süresi önceki yıllarda 120 dakika olarak önerilmiştir; ancak günümüzde bu sürenin 30 dakika solunum parametrelerinde değişim olmadan t-parçasında kalabilmenin yeterli olduğu görüşündedir (8). Hasta 30-120 dakikalık süre t-parçası uygulamasında sıkıntı yaşamaz, hemodinamisi bozulmaz ve arter kan gazı değerlerini normal değerlerde devam ettirebilirse spontan solunuma t- parçasında devam eder. Intolerans bulguları (hemodinamik değişimler ve kan gazı değerlerindeki değişimler) yok ise ekstübasyon gerçekleştirilir $(9,10)$.

T tüp yönteminde, mekanik ventilasyon desteğinin kısa süreli uygulanmasından sonra genellikle ilk denemede başarı sağlanır. Mekanik ventilasyonda kalma süresi uzadığında t tüp yöntemi ilk denemede başarılı olunamayabilir. Ayırma sürecinde, intolerans bulgusu varsa birey yeniden mekanik desteğe alınır ve en az 24 saat sonra spontan solunum denemeleri tekrarlanır (11). Bir farklı yol ise, hasta gün içinde 3-4 kez 5-60 dakikalık spontan solunum denemelerine bırakılır ve gece dinlenmesi sağlanır. Bireyin gün içerisindeki ayırma süreleri arttırılarak aralıklı T-tüp denemesi sağlanır. Süresi ve sıklığı hastanın bireysel özelliklerine ve tolerasyonuna göre değişmektedir $(8,12)$.

T tüp yönteminin avantajl; bireyin spontan solunumunun yeterliliğini test eder. Hastanın solunum işine tamamen katılımı sağlanır ve yorulduğu anda mekanik vantilatör ile dinlenme periyoduna alınabilir. Uyumlu aralıklı zorunlu ventilasyon yöntemi'nden (SIMV- Synchronized Intermitted Mandatory Ventilation) daha hızlı mekanik ventilatörden ayırma süreci sağlar. Dezavantajı ise hastaya solunum iş yükü ani olarak yüklenir. Endotrakeal tüp direnci ve alarm sistemleri devre dışı olduğundan daha yakın izlem sürecini gerektirir. Hastaların yakın takibi için daha fazla personel ve zaman gerekir $(8,13,14)$.

\section{Uyumlu aralıklı zorunlu ventilasyon yöntemi}

Uyumlu aralıklı zorunlu ventilasyon yöntemi (SIMV) bireyin spontan solunumunu yapabilmesi ile birlikte solunum sürecine dahil edilmesini sağlayan bir yöntemdir $(2,12)$. Uyumlu aralıklı zorunlu ventilasyon yöntemi, çoğunlukla kısmi solunum desteği vermek için kullanılır. Zorunlu ventilasyonsayısı arteriyel kan gazları sonucu ve klinik değerlendirme bulguları doğrultusunda kademeli şekilde azaltılır. Genel olarak her basamakta 2 soluk/dk azaltılarak devam edilir. Bireyin mekanik ventilatörde belirlenen miktardaki solunumu kendi solunumu ile eş zamanlı yapılmasını sağlar $(2,15)$. Kademeli olarak cihazın yaptırdığı zorunlu solunum sayısı azaltılarak, solunum işinin büyük bir kısmı hasta tarafına aktarıır (16). Bireyin solunum kaslarını kullanabilmesini sağlar. SIMV frekansı sıfıra düşürüldüğünde birey T-parçasına bağlanır veya ventilatörde sıfır SIMV frekansında bir süre daha tutulur ve sonrasında ekstübe edilir. Klinik çalışmaların içinde en kötü mekanik ventilatörden ayırma sonuçlarına sahiptir $(2,12,15,16)$. T tüp yöntemi ve basınç desteğinden ayırmaya oranla ventilatörden ayırma süresi daha uzundur (12).

Uyumlu aralıklı zorunlu ventilasyon yönteminin avantajı: Ventilatör alarm sistemlerinin kullanımına izin verir. Basınç destek modları ile birlikte uygulanabilir. Minimum dakika ventilasyonunu garanti eder, solunum kas gücünün korunmasını sağlar. Yöntemin dezavantajı; Kademeli olarak cihazın yaptırdığı zorunlu solunum sayısını zamanla azaltarak, solunum işi birey tarafından sağlandığından ayırma süresini uzatır. Ventilatör ayarlanan solunum sayısı ve volümünü zorunlu olarak verir. Bununla birlikte birey zorunlu solunumlar arasında spontan nefes alır ve desenkronizasyon yaşanır. Desenkronizasyon nedeniyle bireyde kas yorgunluğu artar ve solunum işinin artmasına yol açar $(14,17,18,19,20)$.

\section{Basınç destekli ventilasyon yöntemi ( PSV)}

Basınç Destekli Ventilasyon Yöntemi (PSV) birey tetiklemeli ve akım döngülü bir moddur. Kısmi ventilasyon desteği amacıyla kullanılır. Birey tarafından solunum başlatııır. Hastaya verilecek olan basınç desteğinin miktarı solunum desteği ile doğru orantılıdır. Bireyde, aşamalı olarak verilen basınç desteği azaltılır ve solunum kaslarında yorgunluk belirtileri gözlenir (21). Kullanıcı tarafından her bir solunum, seçilen basınç desteği ile desteklendiği için hava yolu direncinin yenilmesi sağlanır (22). Birey 2 saat 
süreyle hedef solunum şekli ve gaz değişimini sağladığında mekanik ventilasyon sonlandırılır. Solunum kaslarının güçlenmesi ve solunum merkeziyle uyumlu sayıda solunumun yapılmasında etkili bir yöntemdir (12).

Basınç Destekli Ventilasyon Yöntemi (PSV) avantajları; spontan solunuma en yakın, en konforlu yöntemdir. Bireyin solunum frekansını ve tidal hacmini belirleyebildiğinden daha az sedasyon ihtiyacı olur. Basınç desteğinin miktarı ile solunum desteği doğru orantılı olduğundan hasta ile vantilatör senkronizasyonunu sağlar. Solunum iş yükünü hastaya birden yüklemez SIMV'den daha hızlı ayırma süreci sağlanır. Kas yorgunluğunun önlenmesinde daha etkili bir yöntemdir (11,19). PSV dezavantajları; Bireye PSV modunda uygulanacak basınç uygulaması daha yakından izlenmesi gerekliliği vardır. Bireyi, cihazda uygulanan desteğin fazla olması apneye sokabilir. Cihazdaki basıncın olması gereken basınç değerinden düşük olması solunum kaslarında yorulmaya yol açar $(14,18,19,23)$.

\section{Mekanik ventilatörden ayırmada hemşirenin rolü}

Mekanik ventilatörden ayırma sürecinde bireyin genel durumu, mevcut hastalığı, kardiyak değerleri ve solunumsal parametreleri ile psikolojik olarak ayırma sürecine hazır olması gereklidir. Bunun yanında iyi bir hemşirelik izlemi son derece önemlidir. Yapılan çalışmalarda mekanik ventilatörden ayırma sürecine hemşirenin katılımı ile başarı oranı arasında pozitif yönlü ilişki olduğu bulunmuştur $(13,24)$. Mekanik ventilatördeki bireyin anksiyete ve panik gibi duygusal ve emosyonel gereksinimlerinin hemşireler tarafından karşılanmasının ventilatör destek süresini azalttığı bildirilmektedir (15). Ayırma stratejisi ya da protokol kullanımıyla karar verme süreci daha güvenli hale gelmektedir. Bu süreçte hemşirenin uygulaması gereken girişimler:

- Hastanın solunum işinin azaltılması ve organların diyafram hareketlerini engellemeyen semi- fowler pozisyonu verilmeli,

- Her hasta için dezenfekte edilmiş nemlendirme sistemi kullanilmalı,
- Ventilatör devrelerinin kıvrılmaması, hastaya uygun boyutta olmasına dikkat edilmeli,

- T-tüpte tıkanıklığa yol açabilecek sekresyonlar aspirasyon işlemi ile temizlenmeli ve hava yolu direnci azaltılmalı, subglottik sekresyonlar her aspirasyonda temizlenmeli,

- Aspirasyon işlemi yapılırken hava yolu içerisine serum fizyolojik enjeksiyonu olmamalı,

- Hastaya klorheksidin ile ağız bakımı verilmeli, dişlerin fiziksel yıkanması ve temizlenmesi her vardiya yapılmalı,

- Yapay hava yolu çıkarılmadan en az dört saat önce hastanın enteral beslenmesi durdurulmalı, aspirasyon pnömonisini önlemeyebilmek için hastanın ekstübasyonundan en az 4 saat sonra beslenmesi sağlanmalı,

- Hastanın mekanik ventilasyondan ayrılmaya hazır olup olmadığı gün boyunca takip edilmeli,

- Hastanın nörolojik değerlendirmesi saat başı yapılmalı,

- Hastaya ağrı değerlendirmesi yapılarak, mümkünse farmakolojik olmayan yöntemlerle ağrı kontrolünün sağlanması,

-Yaşam bulguları monitörden sürekli izlenmeli,

- Sedasyon en aza indirilmeli mümkünse önlenmeli, ekstübasyon işlemi sonrası sık aralıklarla kan gazı kontrolü, SpO2 monitorizasyonu yapılmalı,

- Uygun iletişim teknikleri kullanılarak hastanın anksiyetesinin en aza indirilmeli,

- Mekanik ventilatörde 24 saatten fazla destek alan hastalar için erken mobilizasyona yönelik protokollü rehabilitasyon kullanılmalı $(3,11,17,18,23,25,26)$.

\section{Sonuç}

Yoğun bakım hemşireleri multidisipliner ekip üyeleri içerisinde tedavi ve bakım süreci içerisinde hasta ile uzun süreli birlikteliği olan sağlık profesyonelleridir. Mekanik ventilatörden ayırma sürecinde bireye uygun yöntem seçilmesi önemlidir. Hemşirelerin, mekanik ventilatörden ayrılmaya ilişkin sorumluluklarını yerine getirmesi, ventilatörden ayırma süresinin kısalmasına ve bakım kalitesinin artmasına katkı sağlayacaktır. 


\section{Kaynaklar}

1. Öz H, Köksal MG. İnvaziv Mekanik Ventilasyon. Türkiye Klinikleri J Int Med Sci 2006; 2:89-96.

2. Koyuncu A, Yava A, Kürklüoğlu M, Güler A, Demirkılıç U. Mekanik Ventilasyondan Ayırma ve Hemşirelik. Türk Göğüs Kalp Damar Cerrahisi Dergisi. 2011;19:671-81. [CrossRef]

3. Dankers M, Grosu H, Jean R, Cruz RB, Fidellaga A, Han Q, et al. NurseDriven, Protocol-Directed Weaning From Mechanical Ventilation Improves Clinical Outcomes and is Well Accepted By Intensive Care Unit Physicians. J Crit Care. 2013;28:433-41. [CrossRef]

4. Crocker C. Weaning From Ventilation-Current State of the Science and Art. Nurs Crit Care 2009;14:185-90. [CrossRef]

5. Lavelle C, Dowling M. The Factors which Influence Nurses When Weaning Patients from Mechanical Ventilation: Findings From a Qualitative Study. Intensive Crit Care Nurs 2011;27:244-52. [CrossRef]

6. Tonnelier JM, Prat G, Gal LG, Gobert CG, Renault A, Boles JM, et all. Impact of a Nurses' Protocol-Directed Weaning Procedure on Outcomes in Patients Under Going Mechanical Ventilation for Longer Than 48 Hours: a Prospective Cohort Study with a Matched Historical Control Group. Critical Care 2005;9:83-9. [CrossRef]

7. Irajpour A, Khodaee M, Yazdannik A, Abbasi S. Developing a Readiness Assessment Tool for Weaning Patients Under Mechanical Ventilation. Iran J Nurs Midwifery Res 2014; 19: 273-8.

8. Selek Ç, Özcan EP, Orhun G, Şentürk E, Akıncı ÏÖ, Çakar N. Mekanik Ventilasyondan Weaning Sürecinde T-parçası ile Otomatik Tüp Kompansasyonu (OTK) Yöntemlerinin Karşılaştırılması. Turk J Anaesth Reanim. 2014; 42: 91-5. [CrossRef]

9. Yorgancı K, Topeli İskit A. (Çev). Mekanik Ventilasyonun Sonlandırılması. Ankara, Türkiye: Palme Yayıncılık; 2009. p. 511-27.

10. Gelsthorpe T, Crocker C. A Study Exploring Factors Which Influence the Decisionto Commence Nurse-Led Weaning. Nurs Crit Care 2004:9:213-21.

11. Arnal JM. Clinical Practice Guidelines for Weaning Critically ill Adult Patients from Mechanical Ventilation. 2017. https://www. hamilton-medical.com/pt/News/Newsletter-articles/Article 201704-03 Clinical-practice-guidelines-for-weaning-critically-ill-adultpatients-from-mechanical-ventilation 178b221a-8be7-44b5-a39a47afOf1 aacf7 .html Erişim: 26.08.2019.

12. Geiseler J, Kelbel C. Weaning From Mechanical Ventilation. Weaning Categories and Weaning Concepts. Med Klin IntensivMed Notfmed 2016; 111:208-14. [CrossRef]

13. Taylor F. A Comparative Study Examining the Decision Making Processes of Medicaland Nursing Staff in Weaning Patients From Mechanical Ventilation. Intensive Crit Care Nurs 2006; 22:253-63. [CrossRef]
14. Karcz M, Vitkus A, Papadakos PJ, Schwaiberger D, Lachmann B. State of-the-Art Mechanical Ventilation. J Cardiothoracic and Vasc Anesth 2012; 26: 486-506. [CrossRef]

15. Korkmaz FD, İlçe AÖ. Mekanik Ventilatörden Ayırmada Hemşirenin Rolü. Turkiye Klinikleri J Nurs Sci 2009;1:81-7.

16. Macintyre NR. Respiratory Mechanics in the Patient who is Weaning from the Ventilator. Respir Care 2005; 50:275-86.

17. White AC. Long-Term Mechanical Ventilation. Management Strategies. Respir Care. 2012; 57:889-97. [CrossRef]

18. Schmidt GA, Girard TD, Kress JP, Morris PE, Ouellette DR, Alhazzani W, et al. Official Executive Summary of an American Thoracic Society/ American College of Chest Physicians Clinical Practice Guideline: Liberation from Mechanical Ventilation in Critically III Adults. Am J Respir Crit Care Med. 2017; 195:115-9. [CrossRef]

19. Karakoç E. Temel Mekanik Ventilasyon Modları ve Ayarlamalar. Yoğun Bakım Derg 2007; 7:317-21.

20. Ghodrati M, Pournajafian A, Khatibi A, Niakan M, Hemadi $M H$, Zamani MM. Comparing the Effect of Adaptive Support Ventilation (ASV) and Synchronized Intermittent Mandatory Ventilation (SIMV) on Respiratory Parameters in Neurosurgical ICU Patients. Anesth Pain Med. 2016; 6:e40368. [CrossRef]

21. Jaber S, Petrof JB, Jung B, Chanques G, Berthet JB, Rabuel C, et all. Rapidly Progressive Diaphragmatic Weakness and Injury during Mechanical Ventilation in Humans. Am J Respir Crit Care Med 2011;183:364-71. [CrossRef]

22. Black JM, Hawks JH. Medical-Surgical Nursing: Clinical Management for Positive Outcomes, 8th ed, Philadelphia, Saunders Elsevier; 2009.p. 1880-6.

23. Girard TD, Alhazzani W, Kress JP, Ouellette DR, Schmidt GA, Truwit JD, et al. An Official American Thoracic Society/American College of Chest Physicians Clinical Practice Guideline: Liberation from Mechanical Ventilation in Critically III Adults. Rehabilitation Protocols, Ventilator Liberation Protocols, and Cuff Leak Tests. Am J Respir Crit Care Med. 2017;195:120-33. [CrossRef]

24. Pattison N, Watso J. Ventilatory Weaning: A Case Study of Protracted Weaning. British Association of Critical Care Nurses. 2009; 14:75-85. [CrossRef]

25. Tabaeian SM, Yazdannik A, Abbasi S. Compliance with the Standards for Prevention of Ventilator-Associated Pneumonia by Nurses in the Intensive Care Units. Iran J Nurs Midwifery Res. 2017;22:31-6. [CrossRef]

26. Perren A, Brochard L. Managing The Apparent and Hidden Difficulties of Weaning From Mechanical Ventilation. Intensive Care Med. 2013;39:1885-95. [CrossRef] 